\title{
Review on Performance Evaluation of Machining Characteristics using Vegetable-based Cutting Fluids - An approach towards Green Manufacturing
}

\author{
Mohd. Asif I. Gandhi \\ Assistant Professor, Department of Mechanical Engineering, Anjuman-I-Islam's Kalsekar Technical Campus, Panvel, University \\ of Mumbai \\ masifigandhi@gmail.com
}

\begin{abstract}
Lubricants play a major role in decreasing friction and wear during the machining process. Commercial metal cutting fluids are non-renewable and also produces the harmful effect to the environment as well as the operators. The preparation and disposal cost of mineral oil is an expensive one. To promote sustainable and green manufacturing eco-friendly cutting fluid is the need of an hour. Vegetable oil is preferred as an alternative tocommercial cutting fluid owing to its environmentally friendly, biodegradability, renewable, and less toxic, as well as exceptional lubricating properties. This article discusses the influence of various vegetable oil used for the material removal process and its performance. Vegetable oils significantly enhance the machining characteristics in terms of cutting force, tool wear, and surface quality
\end{abstract}

Keywords

Green Manufacturing, Vegetable Oil, Cutting Fluid, Machining, Cutting Force, Surface Roughness, Tool Wear

Article Received: 10 August 2020, Revised: 25 October 2020, Accepted: 18 November 2020

\section{Introduction}

In the machining process cutting fluids $(\mathrm{CFs})$ plays a vital role in enhancing the material removal rate, and tool life, decreasing the surface finish, machining forces, and tool wear, because of its lubricant effect, cooling, and chip removal properties 1 . A better surface finish was not only preferred for the visual appearance of any manufactured goods, but also better tribological characteristics. Thus, the surface finish was exceptionally essential in estimating the efficiency of machine tools which mainly depends on the cutting conditions and CFs2. In 2005, the volume of lubricants utilized in manufacturing industries was stated about $38 \mathrm{Mt}$ with an anticipated rise of $1.2 \%$ more than the succeeding decade. Almost $85 \%$ of the mineral-based CFs were consumed around the world.The storage and disposal of mineral-based CFs are detrimentaland involve a distinct treatment by an environmental protectionagency (EPA) to eliminate the poisonous elements present inside the $\mathrm{CF}$ beforediscarding 3 .

It is also calculated that the price of CFs, containingprocuring, preparation, preservation, and discardingisabout $16 \%$ of the entire machining costs of a component. The discarding cost of CFs canbe up to 2-4 times of the procuring costs as the CFs are not recyclable and necessitateexclusive treatment preceding disposal4.In contrast, the impacts of CFs on the healthiness and the environment has been questioned in recent times. Owing to the extensive consumption of mineral-basedCFs, it caused considerable environmental pollutions throughout their life cycle5.

A bullish nature in the cost for new CFs and discarding of the commercial CFs withthe mixture of new rules and regulation on the ecological and health safety, which isprojected to become even more rigorousregulation shortly, have led to inclusivesystematic research towards a green manufacturing6. Hence, the industries that paid more attention to green manufacturing via CFs have shifted from biodegradability to renewability over theyears to defend our valuableatmosphere. Green manufacturing aims to minimize harmful waste and pollution. The waste should be recyclableand non-dangerous. Further, the waste should be freely throwaway and should notrequireany additional treatment. Concurrently, several industries start to give more emphasisto green manufacturing. The several aspects of anecologicallymodifiedCFs are recorded in terms of biodegradability, harmfulness, and renewability 7 .

Theincreasingcall for this direction has unlocked an initiative for the progress ofvegetable-based CFs, a new biobased CF, which isecologically friendly, inexhaustible, less poisonous, extremely biodegradable, and safe forthrowing away. The recent developments in bio-based CFs by using various vegetable oils and their influence during machining was reviewed and concluded that these bio-based CFs significantly reduces the environmental issues caused by mineral-based CFs5.A detailed review on eco-friendly CFs on sustainable manufacturing was discussed by 8 . The vegetable-based CFs (VBCFs) like Sunflower oil, Sesame oil, Coconut oil, Groundnut oil, Palm oil, Soybean oil, and Castor oil, etc., can be used for the machining process and enhance the machining performance in terms of surface roughness and tool life. This article will summarize the performance of VBCFs in the machining process.

\section{Effect of VBCFs in turning process}

The application of coconut oil in addition tothe emulsion and a neat CF (immiscible with water) in the machining of AISI 304 austenitic stainless steel was studied. It was found that the performance of coconut oilwas better than other CFs. It was noticed that coconut oil had a significant effect on surface roughness and tool life followed by neat oildue to 
its thermal and oxidative stability9.The performance ofCFs formulated using palm kernel oil and cottonseed oil was experimented against the commercialCF with mineral oil in turning of AISI 4340 steel.The responses like surface roughnessand cutting force were measured during the machining process through coated carbide tools. It was found that the performance of palm kernel and cottonseed oil was better than commercial CFs in terms of least surface roughness and machining force 10

During turning of Inconel-800 alloy, different nano CFs namely Aluminum oxide (Al2O3), Molybdenum disulfide (MoS2), and Graphiteunder minimum quantity lubrication (MQL) condition were applied and measured the cutting force, surface roughness, and tool wear. It was found that the performance of Graphite based nanofluid was better than other fluids. The better performance was obtained due to its good tribological and cooling properties and the structure of Graphite is more covalent, and this considerably influences its performance than other nanofluids 11 .

During turning of Mild steel, Copper, and Aluminium, cutting force was measured and turning was performed with groundnut oil, palm oil, kernel oil, shear butter oil, and coconut oil was used as CF. They found that palm oil and groundnut oilexhibited the better performance in terms of the least cutting force for all the three materials and concluded as the performance of groundnut was better than all other oils 12.AISI 9310 alloy steel was turned with an uncoated carbide tool using vegetable oil as minimum quantity lubrication (MQL) fluid. The responses like chip formation, surface roughness, cutting temperature, and tool wear were measured, and the outcomes were compared with dry and wet conditions. They found that cutting temperature was increased with an increase in speed and feed, chip morphology was not varied with cutting temperature and MQL aided machining performed better than dry and wet conditions in all aspects 13 .

The performance of nano-boric (NB) acid suspension in SAE40 and coconut oil through turning of AISI 1040 steel with cemented carbide tool was investigated. The turning process was carried out with different parameters and measured the cutting temperature, flank wear, and surface roughness. They found that due to the lubricating action of NB acid, the cutting temperature, flank wear, and surface roughness wereconsiderably decreased compared to SAE40 $\mathrm{CF}$. Coconut oil with $0.5 \%$ of $\mathrm{NB}$ acid suspension performed better than SAE40 CF 14.

During the turning of AISI 304 steel, the influence of turning parameters and CFs on surface roughness was examined. The CFs considered were Canola based CFs with $8 \%$ of extreme pressure (EP) additive (CCF-I), Canola based CFs with $12 \%$ of EP additive (CCF-II), Sunflower based CFs with $8 \%$ of EP additive (SCF-I), Sunflower based CFs with $12 \%$ of EP additive (SCF-II), Commercial mineral-based $\mathrm{CF}$ (CMCF), Commercial semi-synthetic $\mathrm{CF}$ (CSSCF). Based on the ANOVA results, CCF-II has a greater influence on surface roughness compared to the other turning parameters and surface roughness was decreased in the succeeding order of CFs: CCF-II, SCF-I, CSSCF, SCF-II, CCF-I, \& CMCF 1.

An attempt was made to substitute the mineral oil andpetroleum-based emulsifier with vegetable-based alternatives (sesame oil and coconut-based emulsifier). They measured the cutting temperature, cutting force, tool wear, and surface roughness during the turning of AISI 1040 steel. They observed that formulated fluid with $10 \%$ coconutemulsifier exhibits a performance like the commercial CF 15.The various CFs were formulated with neem oil and $5 \%, 10 \%, 15 \%$, and $20 \%$ of emulsifier. While turning EN8 steel, the performance of the formulated $\mathrm{CF}$ was evaluated against dry and commercial CF in terms of stability of the CF, cutting temperature, surface roughness, tool wear, and cutting force. They found that formulated CFs were biodegradable and stable. Neem oil with $5 \%$ of emulsifier reduces the temperature, tool wear,and cutting force significantly than other CFs, and neem oil with $10 \%$ of emulsifier provides the least surface roughness. The increase in \%emulsifier decreases the performance due to an increase in viscosity 16.

Olive oil was used as MQL based green CF in turning hardened steel and measured the surface quality and cutting temperature. The experimentally measured outcomes were compared against other coolant systems and found that Olive oil with MQL system was the best system for green manufacturing 17.The performance of $3 \%, 7 \%$, and $10 \%$ of emulsion and a synthetic based VBCF and mineral-based semi-synthetic $\mathrm{CF}$ was measured against turning of AISI 1050 steel in terms of tribological and machining characteristics. They found that both VBCFs performed better than mineral-based CFs in terms of low coefficient of friction, best wettability, considerable cooling ability, and minimum machining force18.

\section{Effect of VBCFs in the milling process}

The CFs and milling parameters were optimized using a Doptimal design with different CFs. They measured the specific energy, surface roughness, and tool life during the milling of AISI 304 steel. They found that while machining with Canola $\mathrm{CF}$ lest specific energy and surface roughness was attained. To enhance the tool life commercial CF was preferred. To enhance the tool life and decrease the energy consumption, all the milling parameters have to maintain at low levels 7. During milling of Aluminium 7075-T6 (A17075-T6) alloy composite, various VBCFs (Palm oil, Soya bean, sunflower, and coconut oil) were employed, and cutting force and vibration was measured. They found that palm oil was the most suitable oil for reducing the cutting force and vibration than other VBCFs owing to its higher viscosity 19 . The performance of various VBCFs like castor, groundnut, cottonseed, palm, rapeseed, and neem oil was evaluated in terms of flank wear during milling of Al7075T6 composite. They found that castor oil performed better in terms of flank wear and vibration due to its higher viscosity. The higher viscosity of castor oil forms a layer to decrease the tool wear 20.

The performance of castor oil, mustard oil, and neem oil was evaluated in terms of surface roughness, and flank wear during milling of Inconel 625. They maintained the flowrate of VBCFs as $60 \mathrm{ml} / \mathrm{hr}$ and found that castor oil exhibits the surface roughness and flank wear of $0.131 \mu \mathrm{m}$ and 0.02077 $\mathrm{mm}$ respectively. The performance of castor oil was better than the other two VBCFs in terms of surface roughness and flank wear. They found reported that high viscosity castor oil developed a thin lubricating layer on the tool-workpiece 
interface and decrease the flank wear 21.The performances of five vegetable oils in the drilling of AISI 316Lstainless steel were investigated and the outcomes like chip formation, cutting force, and tool life were compared against commercial mineral-based oil. They observed that the tool life can be increased up to $177 \%$ and thrust force can be decreased by $7 \%$ using vegetable oil as a lubricant 22 .

During end milling of AISI 304 stainless steel, various CFs like sunflower and canola oil (SCF-II with $8 \%$ extreme pressure (EP), CCF-II without EP and CCF-II with $8 \% \mathrm{EP}$ ) and a commercial type of semi-synthetic $\mathrm{CF}$ ) were employed to investigate the milling performance like milling force, surface roughness, and flank wear. They found that CCF-II with $8 \%$ EP CF exhibited better performance than other CFs 23.During milling of TC4 alloy, MQL with graphene dispersed VBCF was employed as a coolant to enhance the milling characteristics like milling temperature, milling force, surfaceroughness, and surface microhardness. The milling parameters were optimized with Taguchi Principal component analysis - Gray relational analysis and found that graphene dispersed VBCF significantly enhance the milling characteristics 24 .

The performance of kapok and palm oil was evaluated in terms of cutting force, cutting sound, vibration, surface roughness, and flank wear, and the measured outcomes were compared against SAE40 oil. They developed a tool condition monitoring system based on sound and vibration signals. The milling parameters were optimized for minimum surface roughness and flank wear using Response Surface Methodology (RSM). Kapok oil significantly decreases cutting force than SAE40 and palm oil. They found that the performance of palm oil was better than the other two CFs in terms of surface roughness, flank wear, cutting sound, and vibration signals 25 .

The performance of VBCF along with the dispersion of $\mathrm{A} 12 \mathrm{O} 3$ nanoparticles $(0.5,1.0$, and $1.5 \mathrm{vol} \%)$ was evaluated during the milling of Hastelloy C276 alloy in terms of tool life and surface roughness. They found that the addition of 1 vol\% of $\mathrm{Al} 2 \mathrm{O} 3$, tool life was significantly increased by $23 \%$ and $10 \%$ compared to $0.5 \mathrm{vol} \%$ and $1.5 \mathrm{vol} \%$ of nanoparticles due to the rise in thermal conductivity and wettability ability of CF while increasing the concentration of $\mathrm{Al} 2 \mathrm{O} 3$ nanoparticles 26.During the face milling process, the performance of VBCFs like palm oil, and coconut oil were evaluated in terms of surface roughness, and tool wear. The measured outcomes were compared with the commercial CF. The results revealed that coconut oil exhibited better performance than other CFs due to its high thermal and oxidative stability. They found the least tool wear and worn area as $0.16 \mathrm{~mm} 2$, and $0.04 \mathrm{~mm} 2$ respectively 27 .

During milling of Al6061-T6 alloy, coconut oil with NB acid suspension was used as a CF. Cutting temperature and surface roughness were measured under various milling conditions as well as the flowrate of the CF. They found that cutting temperature and surface roughness decreased with an increase in the flowrate of the coconut oil. They concluded that better performance was obtained with coconut oil with $0.5 \mathrm{wt} \%$ of $\mathrm{NB}$ acid suspension 28 . The performance of coconut oil with $0.5 \mathrm{wt} \%$ and $0.9 \mathrm{wt} \%$ of NB acid suspension was evaluated during the face milling of Inconel 625. The outcomes like surface roughness, flank wear, and spindle vibration were measured and the process parameter was optimized using Taguchi's design of experiment. $0.5 \mathrm{wt} \%$ suspension of NB acid in coconut oil significantly decreased the surface roughness, flank wear, and vibration by $3.92 \%$, $6.28 \%$, and $4.85 \%$ respectively. $0.9 \mathrm{wt} \%$ of $\mathrm{NB}$ acid suspension decreased the performance due to its accumulation of particles 29 .

The performance of palm-castor oil (1:0.5 to 1:3) mixture in MQL condition was evaluated in terms of cutting force, surface roughness, and tool wear during the end milling of Inconel 690 alloy. TOPSIS framework was used to select the castor-palm oil mixture ratio and found as 1:2. They found that this selected mixture considerably decrease the surface roughness, cutting force, and tool wear by $16.146 \%$, $7.971 \%$, and $3.155 \%$ respectively 30 . The summary of VBCFs and their performance in terms of the turning and milling process is shown in Table 1.

Table 1. Influence of VBCFs in the machining process

\begin{tabular}{|c|c|c|c|c|c|c|}
\hline S.No. & CF & Workpiece & Response & $\begin{array}{c}\% \\
\text { variation }\end{array}$ & $\begin{array}{l}\text { Operating } \\
\text { condition }\end{array}$ & Reference \\
\hline \multicolumn{7}{|c|}{ Tuming process } \\
\hline \multirow[t]{4}{*}{1.} & \multirow[t]{4}{*}{ VBCF - MQL } & \multirow[t]{4}{*}{$\begin{array}{l}\text { AISI } 9310 \\
\text { low salloy } \\
\text { steel }\end{array}$} & $\begin{array}{l}\text { Chip } \\
\text { reduction } \\
\text { coefficient }\end{array}$ & $-28.57 \%$ & $\begin{array}{ll}\mathrm{Doc} / & 1 \mathrm{~mm} ; \\
\text { Fedd (F) } & 0.1 \\
\mathrm{~mm} / \mathrm{rev}\end{array}$ & Is \\
\hline & & & $\begin{array}{l}\text { Average } \\
\text { principal } \\
\text { Flank wear }\end{array}$ & $-27.78 \%$ & $\begin{array}{l}\text { DoC- } 1 \mathrm{~mm} ; \mathrm{F} \\
0.8 \mathrm{~mm} / \mathrm{rev}\end{array}$ & \\
\hline & & & $\begin{array}{l}\text { Average } \\
\text { suxiliary } \\
\text { Flank wear }\end{array}$ & $-6.67 \%$ & $\begin{array}{l}\text { DoC- } 1 \mathrm{~mm} ; \mathrm{F} \\
0.8 \mathrm{~mm} / \mathrm{rev}\end{array}$ & \\
\hline & & & $\begin{array}{l}\text { Surface } \\
\text { roughness }\end{array}$ & $-50 \%$ & $\begin{array}{l}\text { DoC- } 1 \mathrm{~mm} ; \mathrm{F} \\
0.8 \mathrm{~mm} / \mathrm{rev}\end{array}$ & \\
\hline \multirow[t]{2}{*}{2.} & \multirow{2}{*}{$\begin{array}{l}\text { Coconut oil } \\
0.5 \mathrm{w} 1 \% \text { of } \mathrm{NB} \text { acid } \\
\text { (SAE }+0.5 \mathrm{w} 1 \% \text { of } \\
\mathrm{NB} \text { acid) }\end{array}$} & \multirow[t]{2}{*}{$\begin{array}{l}\text { AISI } 1040 \\
\text { steel }\end{array}$} & Flank wear & $-14.06 \%$ & \begin{tabular}{|l|} 
Cutting spesd \\
(CS) $100 \mathrm{~m} / \mathrm{min}$
\end{tabular} & \\
\hline & & & $\begin{array}{l}\text { Surface } \\
\text { roughness }\end{array}$ & $-12 \%$ & CS $100 \mathrm{~m} / \min$ & \\
\hline \multirow[t]{4}{*}{3.} & \multirow[t]{2}{*}{ LB2000 } & \multirow[t]{4}{*}{$\begin{array}{l}\text { Inconel } \\
718\end{array}$} & Tool life & $\begin{array}{l}12 \% \\
\text { (compared } \\
\text { with dry) }\end{array}$ & \multirow[t]{3}{*}{$\begin{array}{l}\text { CS } 250 \mathrm{~m} / \mathrm{min} \text {, } \\
\text { F } 0.1 \mathrm{~mm} / \mathrm{rev} \text {, } \\
\text { DoC } 0.5 \mathrm{~mm} \text {. }\end{array}$} & \\
\hline & & & & \begin{tabular}{|l}
$+46 \%$ \\
(compared \\
to MQL)
\end{tabular} & & \\
\hline & \multirow[t]{2}{*}{$\mathrm{LB} 2000+\mathrm{MoS}_{2}$} & & & $\begin{array}{l}-22 \% \\
\text { (compared } \\
\text { to } \\
\text { Graphite) }\end{array}$ & & \\
\hline & & & $\begin{array}{l}\text { Surfaces } \\
\text { roughneass }\end{array}$ & $-35 \%$ & $\begin{array}{l}\mathrm{CS}: 300 \mathrm{~m} / \mathrm{min}, \\
\mathrm{F}: 0.1 \mathrm{~mm} / \mathrm{rev},\end{array}$ & \\
\hline
\end{tabular}




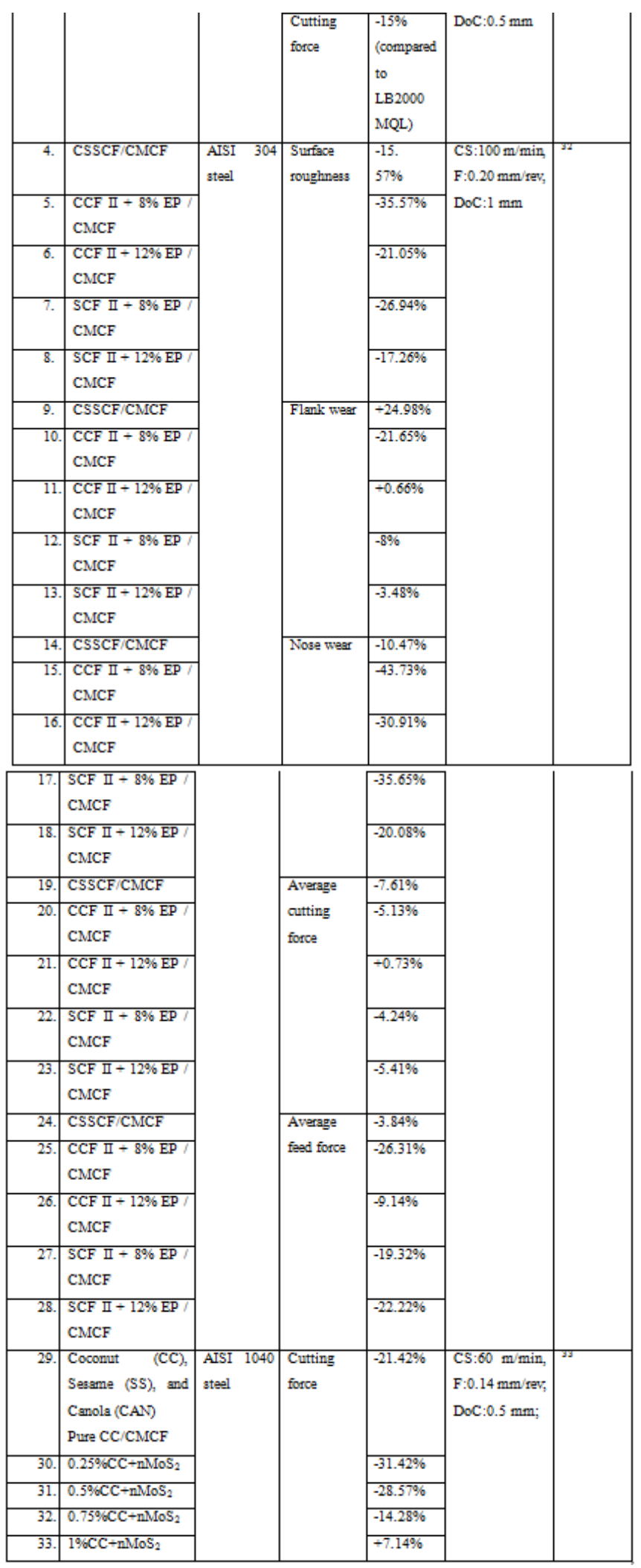

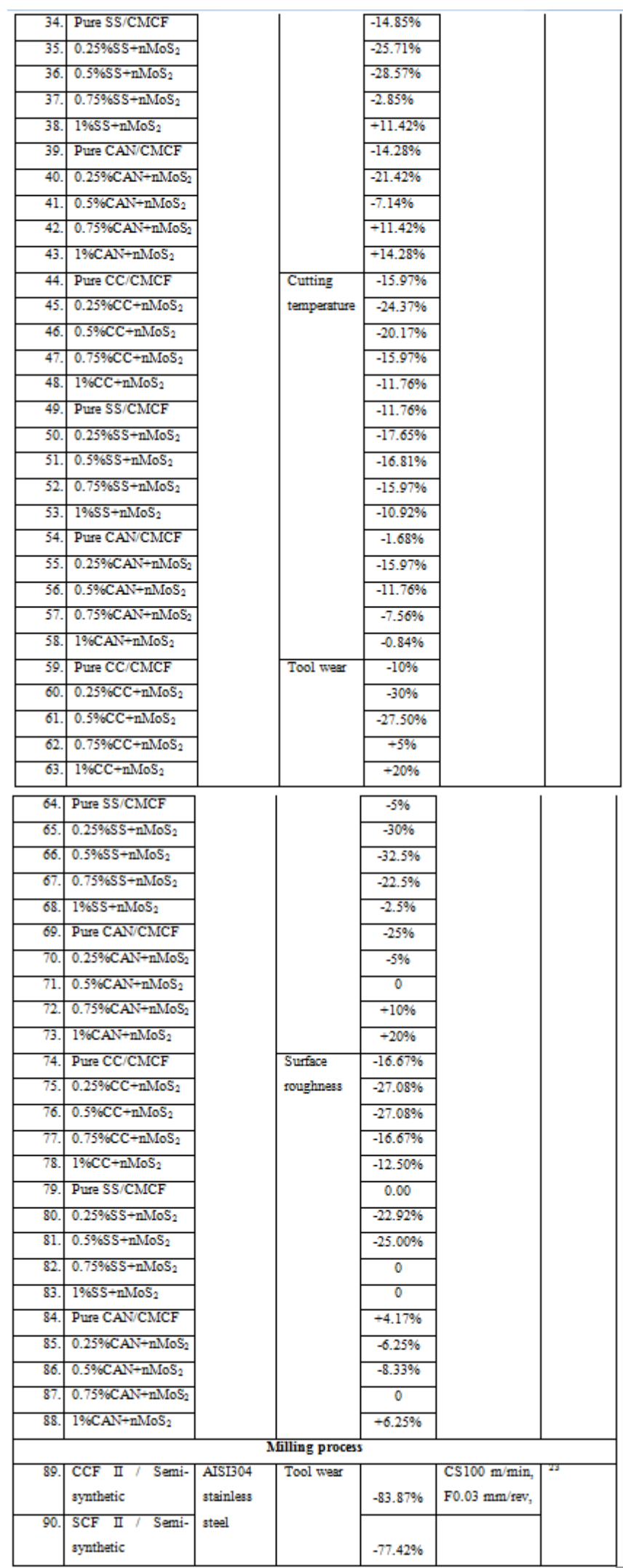




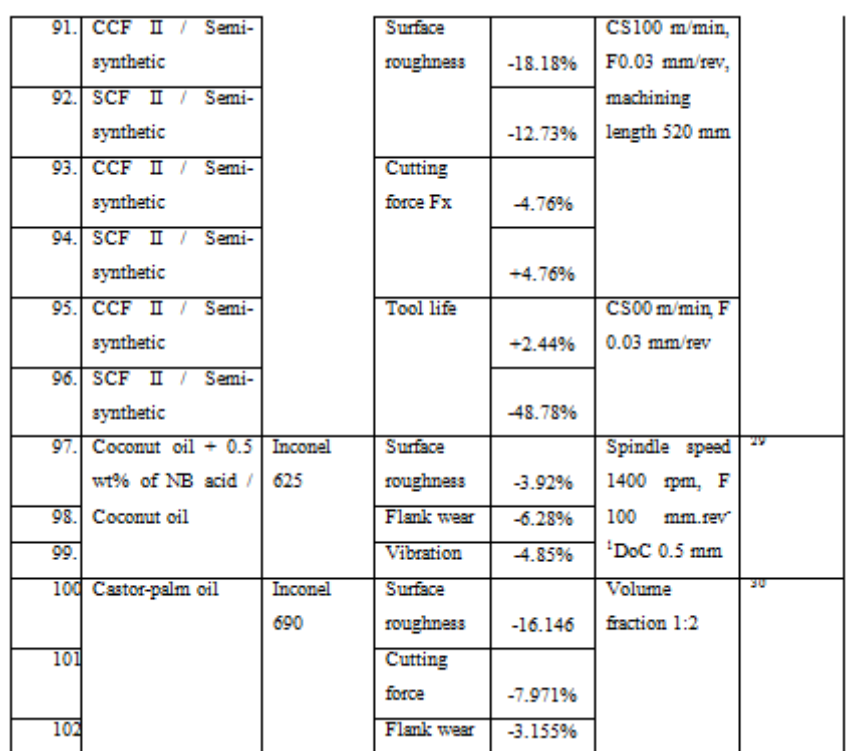

\section{Discussion}

Various researchers reported that the VBCFs withthe MQL method has better performance than the standard lubrication method (flood condition). The reasons for these results are discussed below:

- The fatty acid and triglyceride are the major ingredient of vegetable oil. Owing to the presence of fatty acid and triglyceride in vegetable oils, various polar groups like $-\mathrm{COOH}$ and $-\mathrm{COOR}$ are formulated.

- $\quad$ Figure 1illustrates the polar group of vegetable oil. It was found that extraordinary lubrication characteristics of vegetable oil are due to the presence of polar groups 5 .

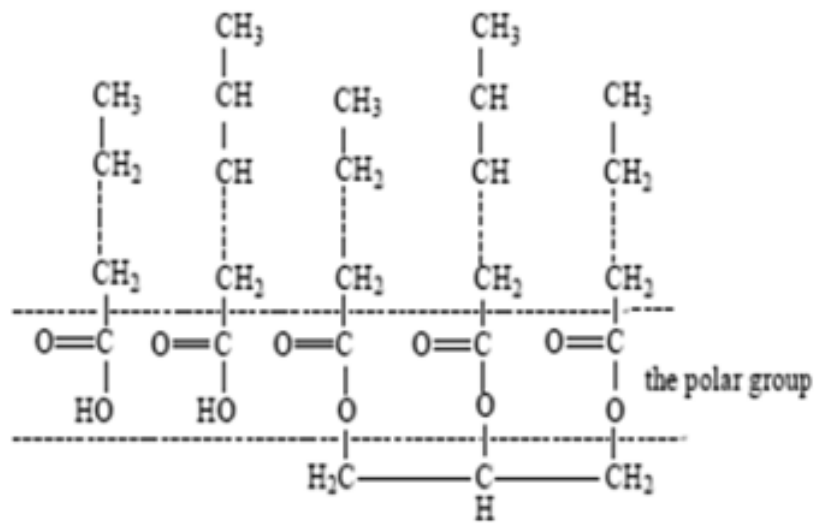

Figure 1. A polar group in vegetable oil 5
Polar groups perform like a smallbar magnet and articulated a lubricating oil film as shown in Figure 2.This formulated lubricating oil film on the workpiece considerably decrease the friction and wear.

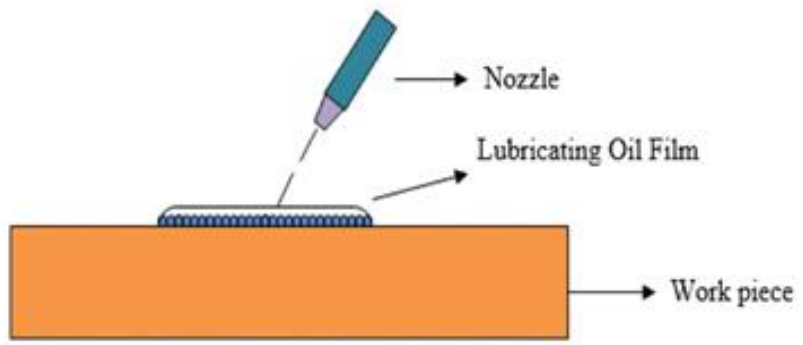

Figure 2. Lubricating oil film8

Around $100^{\circ} \mathrm{C}$ temperature, polar groups present in VBCFs respond with the workpiece and forms a metallic soap file ascribed to enhance the lubricity of the oil 34 .

The fatty acid chain inVBCF is made of many nonpolar methyl groups. Thus, a dispersion force called as London dispersion force is acting between the molecules as depicted in Figure 3.

As aresult, the immediate dipole of the molecule makesthe neighboring molecule produce dipoles. Hence, two molecules are attracted to each other. As the number of carbon molecules is raised, subsequently dispersion force is also enhanced 35 .

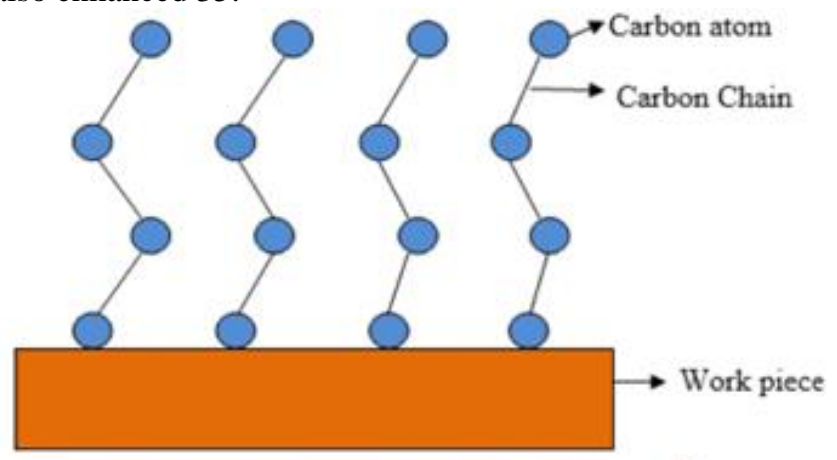

Figure 3. Dispersion force acting between the molecules 35

In general, vegetable oilsdelivers high viscosity at elevated temperature and hold for a long time, which helps enhanced lubrication characteristics during the material removal process 34 .

Lubricant with nanoparticles is a new engineering material that has nanoparticles dispersed in a base fluid which could be an efficientapproach to decrease the wear and friction during the machining process. Nanoparticles have shown an immense potential to be an ideal and efficient alternate way to flood lubrication owing to its environmental concerns. During machining of GH4169,the lubrication ability of various VBCFs was analyzed and the following ranking was given: Maize <Rapeseed < Soybean < Sunflower<Peanut $<$ Palm $<$ Castor oil. This indicates maize oil had the better lubrication ability followed by rapeseed oil 35 . The lubrication ability of castor oil was very less due to its very high viscosity. Though castor oil is not preferred for the machining process, palm oil can be preferred as an alternative to castor oil owing to its flowability and good polarity36. 


\section{Conclusion and Future scope}

Cutting fluids (CFs) play a significant role in the material removal process and tribological applications. Owing to the cost, environmental concerns, and disposal issues, mineralbased CFs are not suitable for green and sustainable manufacturing. As an alternative to mineral-based $\mathrm{CFs}$ and focus on green manufacturing, VBCFs have good tribological and lubrication properties. VBCFs significantly enhance the machining characteristics in terms enhance the surface finish and tool life and decrease the cutting force and cutting energy.

Further tribological properties can be enhanced by adding the additives (micro and nanoparticles) and viscosity modifiers like Ethylene-vinyl acetate copolymer (EVA) and ethyl cellulose (EC) to enhance the lubricant properties. The mixture of palm and castor and other oils can be an alternative to enhance the lubricant properties. Further research can be initiated in the direction of preparing nanofluids to enhance the machining performance and decrease the processing and disposal cost of CFs

\section{References}

[1] Cetin MH, Ozcelik B, Kuram E and Demirbas E. Evaluation of vegetablebased cutting fluids with extreme pressure and cutting parameters in turning of AISI 304L by Taguchi method. Journal of Cleaner Production. 2011; 19: 2049-56.

[2] Davim JP, Gaitonde V and Karnik S. Investigations into the effect of cutting conditions on surface roughness in turning of free machining steel by ANN models. Journal of materials processing technology. 2008; 205: 16-23.

[3] Zhang JZ, Rao $\mathrm{P}$ and Eckman $\mathrm{M}$. Experimental evaluation of a bio-based cutting fluid using multiple machining characteristics. wear. 2012; 12: 13-4.

[4] Shokrani A, Dhokia V and Newman ST. Environmentally conscious machining of difficult-to-machine materials with regard to cutting fluids. International Journal of machine Tools and manufacture. 2012; 57: 83-101.

[5] Debnath S, Reddy MM and Yi QS. Environmental friendly cutting fluids and cooling techniques in machining: a review. Journal of cleaner production. 2014; 83: 33-47.

[6] Tschätsch H and Reichelt A. Cutting fluids (coolants and lubricants). Applied
Machining Technology. Springer, 2009, p. 349-52.

[7] Kuram E, Ozcelik B, Bayramoglu M, Demirbas E and Simsek BT. Optimization of cutting fluids and cutting parameters during end milling by using D-optimal design of experiments. Journal of Cleaner Production. 2013; 42: 159-66.

[8] Sen B, Mia M, Krolczyk G, Mandal UK and Mondal SP. Eco-friendly cutting fluids in minimum quantity lubrication assisted machining: a review on the perception of sustainable manufacturing. International Journal of Precision Engineering and Manufacturing-Green Technology. 2021; 8: 249-80.

[9] Xavior MA and Adithan M. Determining the influence of cutting fluids on tool wear and surface roughness during turning of AISI 304 austenitic stainless steel. Journal of materials processing technology. 2009; 209: 900-9.

[10] Lawal SA, Choudhury IA and Nukman Y. Evaluation of vegetable and mineral oil-inwater emulsion cutting fluids in turning AISI 4340 steel with coated carbide tools. Journal of cleaner production. 2014; 66: 610-8.

[11] Gupta MK, Jamil M, Wang X, et al. Performance Evaluation of Vegetable OilBased Nano-Cutting Fluids in Environmentally Friendly Machining of Inconel-800 Alloy. Materials. 2019; 12: 2792.

[12] Ojolo S, Amuda M, Ogunmola $\mathrm{O}$ and Ononiwu C. Experimental determination of the effect of some straight biological oils on cutting force during cylindrical turning. Matéria (Rio de Janeiro). 2008; 13: 650-63.

[13] Khan M, Mithu M and Dhar NR. Effects of minimum quantity lubrication on turning AISI 9310 alloy steel using vegetable oil-based cutting fluid. Journal of materials processing Technology. 2009; 209: 5573-83.

[14] Vamsi Krishna P, Srikant RR and Nageswara Rao D. Experimental 
investigation on the performance of nanoboric acid suspensions in SAE-40 and coconut oil during turning of AISI 1040 steel. International Journal of Machine Tools and Manufacture. 2010; 50: 911-6.

[15] Srikant RR and Ramana VSNV. Performance evaluation of vegetable emulsifier based green cutting fluid in turning of American Iron and Steel Institute (AISI) 1040 steel - an initiative towards sustainable manufacturing. Journal of Cleaner Production. 2015; 108: 104-9.

[16] Katna R, Singh K, Agrawal N and Jain S. Green manufacturing-performance of a biodegradable cutting fluid. Materials and Manufacturing Processes. 2017; 32: 15227.

[17] Mia M, Gupta MK, Singh G, Królczyk G and Pimenov DY. An approach to cleaner production for machining hardened steel using different cooling-lubrication conditions. Journal of Cleaner Production. 2018; 187: 1069-81.

[18] Carvalho DOA, da Silva LRR, Sopchenski L, Jackson MJ and Machado ÁR. Performance evaluation of vegetable-based cutting fluids in turning of AISI 1050 steel. The International Journal of Advanced Manufacturing Technology. 2019; 103: 1603-19.

[19] Shankar S, Mohanraj T and Ponappa K. Influence of vegetable based cutting fluids on cutting force and vibration signature during milling of aluminium metal matrix composites. Jurnal Tribologi. 2017; 12: 117.

[20] Mohanraj T, Shankar S, Rajasekar R, Deivasigamani $\mathrm{R}$ and Arunkumar PM. Tool condition monitoring in the milling process with vegetable based cutting fluids using vibration signatures. Materials Testing. 2019; 61: 282-8.

[21] Shankar S, Mohanraj T and Pramanik A. Tool condition monitoring while using vegetable based cutting fluids during milling of inconel 625. Journal of Advanced Manufacturing Systems. 2019; 18: $563-81$.
[22] Belluco W and De Chiffre L. Performance evaluation of vegetable-based oils in drilling austenitic stainless steel. Journal of materials processing technology. 2004; 148: 171-6.

[23] Kuram E, Ozcelik B, Simsek BT and Demirbas E. The effect of extreme pressure added vegetable based cutting fluids on cutting performance in milling. Industrial Lubrication and Tribology. 2013.

[24] Li M, Yu T, Yang L, Li H, Zhang R and Wang W. Parameter optimization during minimum quantity lubrication milling of TC4 alloy with graphene-dispersed vegetable-oil-based cutting fluid. Journal of Cleaner Production. 2019; 209: 150822.

[25] Shankar S, Manikandan M, Raja G and Pramanik A. Experimental investigations of vibration and acoustics signals in milling process using kapok oil as cutting fluid. Mechanics \& Industry. 2020; 21: 521.

[26] Günan F, Kıvak T, Yıldırım ÇV and Sarkaya M. Performance evaluation of MQL with AL2O3 mixed nanofluids prepared at different concentrations in milling of Hastelloy C276 alloy. Journal of Materials Research and Technology. 2020; 9: 10386-400.

[27] Nasution AR, Fuadi Z, Hasanuddin I and Kurniawan R. Effect of vegetable oils as cutting fluid on wear of carbide cutting tool insert in a milling process. IOP Conference Series: Materials Science and Engineering. IOP Publishing, 2020, p. 012001.

[28] Siddiqui T and Singh M. Experimental investigations on the performance of nanoboric acid suspensions in coconut oil during milling operation on Al 6061-T6 alloy. IOP Conference Series: Materials Science and Engineering. IOP Publishing, 2020, p. 012006.

[29] Mohanraj T, Ragav P, Gokul E, Senthil P and RAGHUL ANANDH $\mathrm{K}$. EXPERIMENTAL INVESTIGATION OF COCONUT OIL WITH NANOBORIC 
ACID DURING MILLING OF INCONEL

625 USING TAGUCHI-GREY

RELATIONAL ANALYSIS. Surface

Review and Letters. 2020: 2150008.

[30] Sen B, Gupta MK, Mia M, Pimenov DY and Mikołajczyk T. Performance Assessment of Minimum Quantity CastorPalm Oil Mixtures in Hard-Milling Operation. Materials. 2021; 14: 198.

[31] Marques A, Suarez MP, Sales WF and Machado ÁR. Turning of Inconel 718 with whisker-reinforced ceramic tools applying vegetable-based cutting fluid mixed with solid lubricants by MQL. Journal of Materials Processing Technology. 2019; 266: 530-43.

[32] Ozcelik B, Kuram E, Cetin $\mathrm{MH}$ and Demirbas E. Experimental investigations of vegetable based cutting fluids with extreme pressure during turning of AISI 304L. Tribology International. 2011; 44: 1864-71.

[33] Padmini R, Krishna PV and Rao GKM. Effectiveness of vegetable oil based nanofluids as potential cutting fluids in turning AISI 1040 steel. Tribology International. 2016; 94: 490-501.

[34] Jianzhong WJZ. On formation and breakup of boundary lubricating layer [J]. Lubrication Engineering. 2005; 6.

[35] Wang Y, Li C, Zhang Y, et al. Experimental evaluation of the lubrication properties of the wheel/workpiece interface in minimum quantity lubrication (MQL) grinding using different types of vegetable oils. Journal of Cleaner Production. 2016; 127: 487-99.

[36] Li B, Li C, Zhang Y, Wang Y, Jia D and Yang M. Grinding temperature and energy ratio coefficient in MQL grinding of hightemperature nickel-base alloy by using different vegetable oils as base oil. Chinese Journal of Aeronautics. 2016; 29: 1084-95. 